\title{
Estimation of consequences following an atmospheric radioactive emission in a forest ecosystem
}

\author{
P. Calmon \\ Institute of Protection and Nuclear Safety, Division of Environmental Protection, \\ Laboratory of Environmental Modelling, 13108 Saint-Paul-lez-Durance cedex, France
}

\begin{abstract}
Forests represent very efficient filters of atmospheric aerosols. Radionuclides that are fixed on those aerosols fall on the aerial part of trees and understorey (leaves, branches and trunks) and on the soil (litter, mosses and first soil layers). Due to the high content of organic matters in the forest soils and the existence of a nutrition cycle by the humification process, radionuclides show a higher biodisponibility than in agricultural soils. IPSN developed, in collaboration with a finnish team from STUK (Finnish Nuclear Safety Authority), a model to assess the consequences of an atmospheric radioactive emission in a forest ecosystem. This dynamic compartment model has been developed with a simple and operational objective of crisis management. This model needs data relative to dry and wet depositions that are distributed in the ecosystem to trees, understorey and soil. Calculation of transfers between the different compartments of the ecosystem are used to calculate concentrations in forest products and external exposure. Then, ingestion dose and external exposure are calculated for several population groups : six age groups for the population, forest workers, hunters and mushroom and berry pickers. Calculations are made for iodine, caesium, strontium and plutonium isotopes and for three generic forest types : coniferous, deciduous and mixed forests. Forest structures vary in Europe with climate and soil type and also due to forest management. Many parameters in the model database are regional and should be adapted in order to substantially improve the estimations.
\end{abstract}

\section{INTRODUCTION}

In the French post-accident software ASTRAL (Technical ASsistance for post-Accident Radioprotection) [1], a specific model has been developed for forests, because of the unique ecosystem structure and the dynamic behaviour of radionuclides in this environment. The long residence times of radionuclides in forest vegetation and surface soil result in increased intemal and external human doses over decades.

One forest type out of three (deciduous, coniferous and mixed forests) can be selected. The user can choose one mushroom group out of four (classed by cesium affinity), either bilberries or raspberries and one game animal out of eight (brown hare, mountain hare, roe deer, red deer, moose, wild boar, terrestrial birds and waterfowl).

Concentrations in these forest products, ingestion doses and external exposure from sixteen radionuclides $\left({ }^{134} \mathrm{Cs},{ }^{137} \mathrm{Cs},{ }^{131} \mathrm{I},{ }^{103} \mathrm{Ru},{ }^{106} \mathrm{Ru},{ }^{89} \mathrm{Sr},{ }^{90} \mathrm{Sr},{ }^{237} \mathrm{~Np},{ }^{239} \mathrm{~Np},{ }^{238} \mathrm{Pu},{ }^{239} \mathrm{Pu},{ }^{240} \mathrm{Pu},{ }^{241} \mathrm{Pu},{ }^{241} \mathrm{Am}\right.$, ${ }^{242} \mathrm{Cm}$ and ${ }^{244} \mathrm{Cm}$ ) distributed in forests can be predicted each day between deposition and three years after. Doses are calculated for the population by six age classes (babies, very young children, young children, children, teenagers and adults) and for some special groups (mushroom and berry collectors, hunters and foresters). One of the endpoints of ASTRAL is to calculate total human doses through the agricultural and forest pathways. The results can be presented by tables, pies or maps if connected to a cartographic representation tool.

Many parameters in the model are regional, but in a first step they are fixed for the whole French territory and default values are coming from Central European data. 


\section{MODEL DESCRIPTION}

The ASTRAL forest module receives data on time-integrated air concentrations and total wet deposition to the ground from an IPSN atmospheric dispersion software (CONRAD) to which it can be connected. Then, the deposition submodule calculates dry and wet deposition and distributes it to each compartment (canopy, trunk, understorey and soil) of the forest ecosystem. Dry deposition is estimated using deposition velocities and relative leaf area indices with respect to season. The total wet deposition received by an area is distributed to the different forest compartments and soil. The subsequent intercepted fractions vary, depending on forest structure (leaf area index and forest density), weather conditions (rainfall) during the cloud passage. The method is based on information on throughfall in forests [2],[3] and on the approach described in ECOSYS-87 [4].

After deposition, the initial distribution of radionuclides in a forest changes continuously, and in a few days, the tree canopy loose a considerable fraction of the intercepted radioactive material that is transferred to the understorey vegetation and soil. The weathering has an influence on the fractions removed from the vegetation surface. Litterfall, especially of leaves in autumn and needles, transfers both external and internal contaminants from trees to the forest floor. A fraction of the deposited material can be absorbed through the foliar and twig surfaces and transported throughout the tree in case of mobile elements. After the external contaminants have been removed from the tree canopies and understorey, the annual change in the radionuclide content is mainly controlled by the root uptake. The soil compartment receives radioactive material directly from the fallout and from all types of forest vegetation through weathering and litterfall. However, the availability of radionuclides to plants is delayed due to the vertical migration and dissolution of particle-bound radionuclides. Surface runoff can be significant during snow melt and rainy seasons, especially in alpine regions. When the topography is flat, even the first-year runoff from forests on mineral soils is only a few per cent of the total deposited radioactivity [5]. Vertical activity distribution in soil varies by vegetation type, forest structure, soil type and rainfall. In forests, the migration of radionuclides in soil is delayed from that in open areas due to processes of nutrient uptake by trees.

The transfers of radionuclides between the model compartments (Figure 1) are described by a series of first order differential equations.

Radionuclide concentrations in mushrooms, beries and game are calculated by using transfer coefficients from vegetation or soil to edible part of forest products during hunting season and berry or mushroom picking. Outside these periods, radionuclide concentration is derived from the activity of wild food products at the end of these seasons, with the correction of radioactive decay. Changes in activity concentration during culinary preparation are not considered because the reduction factor is generally low and many of wild food products can be fresh eaten.

A contaminated forest as a source of human external exposure is modelled with three compartments: tree canopies, trunks and soil plus understorey vegetation. Understorey and soil are defined as a 'ground layer'. In relation to external radiation, the total (surface, available and fixed soil) activity in soil is used. The two layers of trees (canopies and trunks) plus air constitute a "forest equivalent medium" (FEM) which interacts with photon radiation. These layers are assumed to be homogeneous, and horizontally infinite or semi-infinite. The time that people spend in forests for work or recreation is used to derive external doses. 
Time integrated activity concentrations in air

Total activity deposited by rain
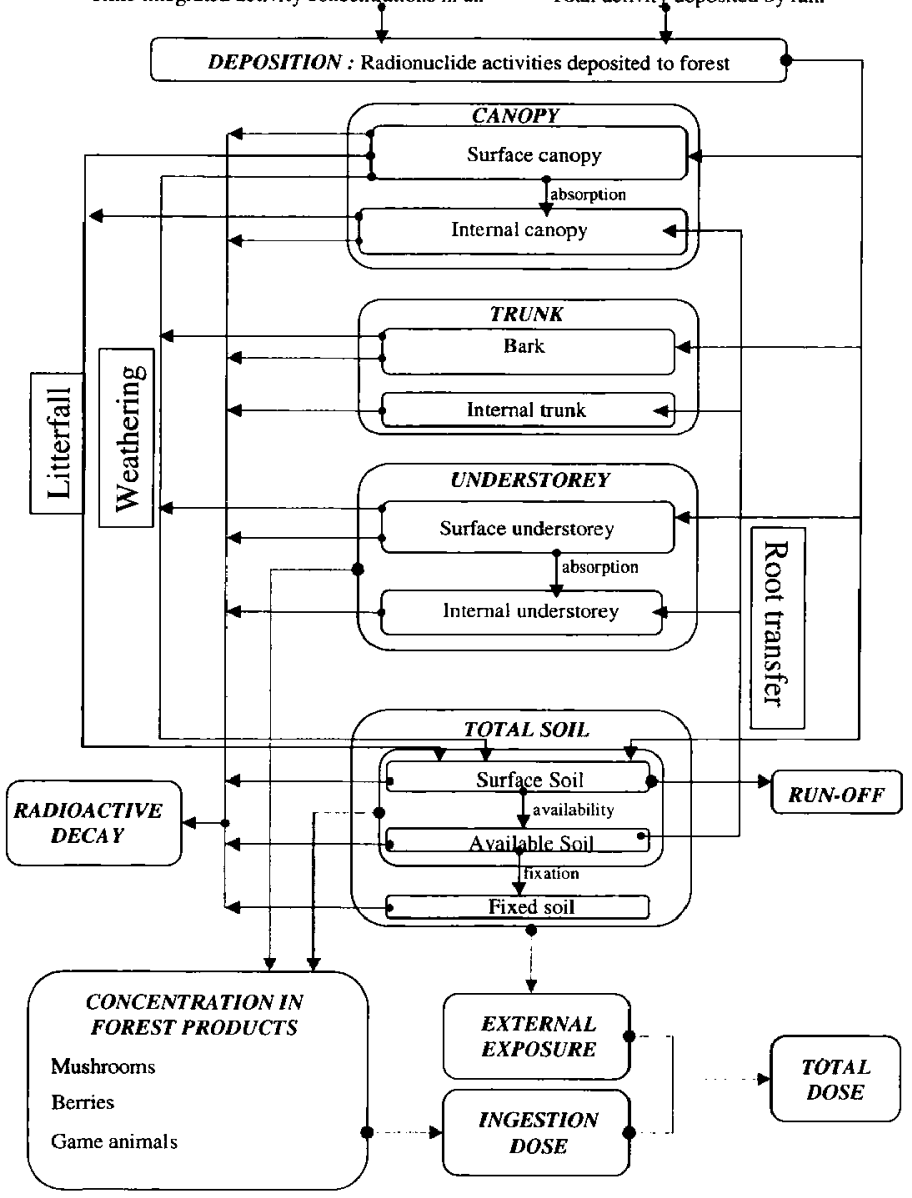

Figure 1 : Schematic diagram showing the different compartments and fluxes of the forest modei. 


\section{RESULTS}

The International Atomic Energy Agency's (IAEA) programme on BIOsphere Modelling and ASSessment methods (BIOMASS) provided a convenient forum for model comparison. The timedependent radiocaesium concentrations in different forest products are derived from ASTRAL and compared in a model-data test set up for BIOMASS, biospheric processes, forest working group.

This post-Chemobyl scenario was for an ukrainian pine dominant mixed forest. The deposited ${ }^{137} \mathrm{Cs}$ activity the first May 1986 was $555000 \mathrm{~Bq} \mathrm{~m}$. Observed values were available from the early 1990s onwards, and the calculation endpoints were given for 12 years after 1986. The following models participated in the test : FORESTLAND from SSI in Sweden, FOA from NDRE in Sweden, FORESTLIFE from BFI in Belarus, FORESTPATH from Harvard University in USA, ECORAD from MSU in Russia, RIFE from Imperial College in UK and the forest model from IPSN in France and STUK in Finland. The results for ${ }^{137} \mathrm{Cs}$ activity concentrations in roedeer meat and in bilberry fruit are presented in figures 2 and 3 . The results of the model presented in this paper are somewhat lower than observed values, but in the range of other model predictions. The geographic origin of data used for parameter estimation may explain part of the difference. The IPSN-STUK parameter values are mainly based on measurements in westem and northem Europe and are therefore not so dominated by East-European data as some other models.

Cs-137 concentration in bliberries

(Bq/ $\mathrm{kg}$ fresh weight)

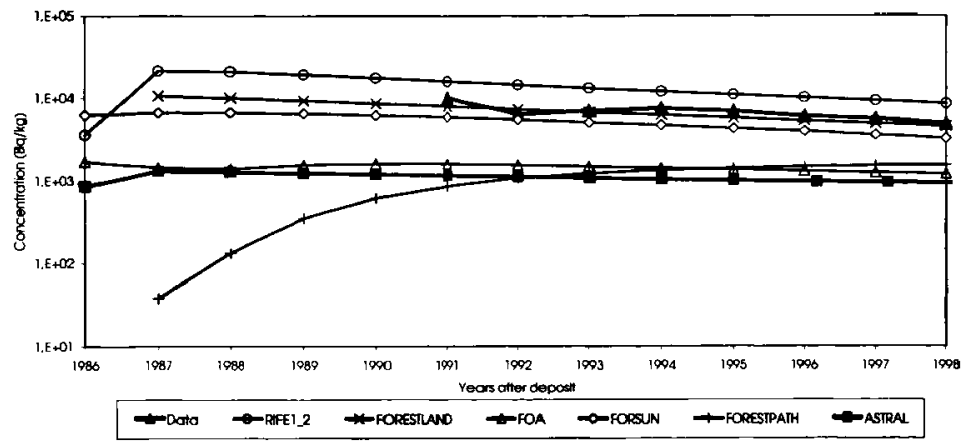

Figure 2 : Comparison of model results and observed ${ }^{137} \mathrm{Cs}$ activity concentrations $\left(\mathrm{Bq} \mathrm{kg}^{-k}\right.$ fw) in bilberries (International Atomic Energy Agency, to be published). 


\section{Cs- 137 concentration in roe deer}

(Bq/kg fresh weight)

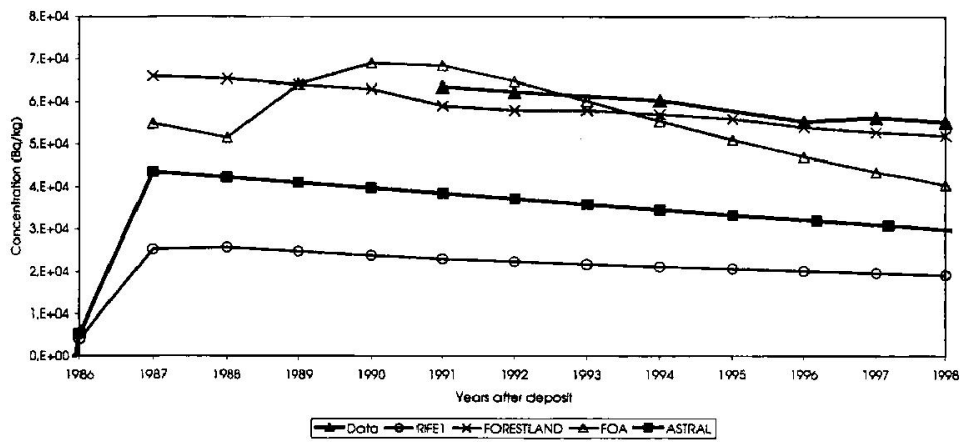

Figure 3 : Comparison of model results and observed ${ }^{137} \mathrm{Cs}$ activity concentrations $\left(\mathrm{Bq} \mathrm{kg}^{.1}\right.$ fw) in roedeer meat (International Atomic Energy Agency, to be published).

ASTRAL can provide also results about evolution and distribution of doses. The figure $n^{\circ} 4$ shows how the ingestion dose is distributed between food products. and especially forest products, three years after deposition. The results are given for a special group : hunters.

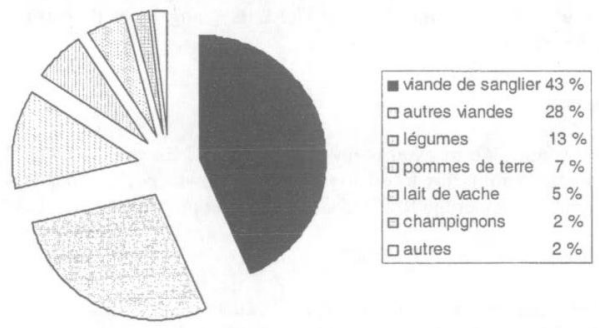

Figure 4 : Contribution of food to ingestion dose (total ingestion dose $=2,910^{-2} \mathrm{~Sv}$ ).

Wild boar meat represents nearly halt of the ingestion dose. This is related to a higher rate of consumption of game meat than for the rest of the population. However this rate is moderate, since it is proposed in ASTRAL at $15 \mathrm{~kg}$ per year for hunters. 
For hunters, the figure $n^{\circ} 5$ illustrates how different kind of doses are distributed.
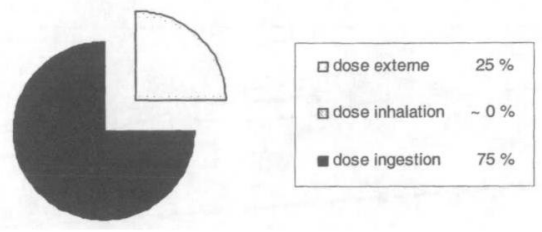

Figure 5 : Distribution of doses (total dose $=3,910^{2} \mathrm{~Sv}$ ).

It can be observed that ingestion dose dominates by far, but external exposure could be important in case of banning of forest products or application of countermeasures.

\section{CONCLUSION}

The current version of the forest model integrated in ASTRAL version 2 can be used to predict concentrations in forest products and radiation doses (ingestion and extemal exposure) from contaminated forests after a radioactive deposit. A set of significant radionuclides are included in the database of the module. However, the reliability of data varies by nuclides, and the most comprehensive information on environmental transfer was available for radiocaesium. The doses through ingestion are modelled using data collected in several countries after the Chernobyl accident. Many of the model parameters are regional and some of them have only been fixed as default values because specific information is lacking. These parameters should be adjusted for a better adequacy to local conditions.

Validation of the forest model in ASTRAL is going on with particular emphasis put on other radionuclides than cacsium.

\section{Acknowledgments}

The author would like to express his gratitude to A. Rantavaara (STUK, Helsinki) for the fruitful collaboration in elaborating this forest model and acknowledges the financial support received from the European Commission under the RODOS Customisation project (contract FI4P-CT96-0053).

\section{References}

[1] Calmon, P. and Mourlon, C. (2001). Equations et paramètres du logiciel ASTRAL V2. IPSN/DPRE/SERLAB report $n^{\circ}$ 01-19 (to be published).

[2] Päivänen, J. (1966) The distribution of rainfall in different types of forest stands. Silva Fennica 119. Helsinki. (In Finnish with English summary).

[3] Seppänen, M. (1964) On the distribution of rainfall in the pine stands. Acta Forestalia Fennica 76. Helsinki. (In Finnish).

[4] Müller, H. and Pröhl, G. (1993) ECOSYS-87: A dynamic model for assessing radiological consequences of nuclear accidents. Health Physics, 64, 232-252.

[5] Nylén, T. and Ericsson, A. (1996) Uptake and retention of radioactive caesium in Scots pine. In: T. Nylén, Uptake, tumover and transport of radiocaesium in boreal forest ecosystems. Doctoral thesis. FOA-R--96-00242-4.3--SE. 